\title{
Application of Multimedia Interactive Technology in Network Courseware
}

\author{
Pengcheng Zhao* \\ Cloud Computing Technology Co., Ltd., Zhuzhou 412000, China. E-mail: zhaopcheng @ 163.com
}

\begin{abstract}
With the development of my country's economy and society, my country's education is also constantly developing, especially since the reform of the new curriculum standards, my country's education has developed more rapidly. This article mainly introduces the interactive technology of multimedia courseware. First, by consulting relevant literature, I fully understand the technology and application of interactive multimedia courseware in teaching, and then understand the advantages of using this technology in teaching, and then use cases to teach, using interactive multimedia courseware and not using interactive multimedia courseware for analysis, and based on relevant theoretical knowledge, put forward some corresponding strategies and opinions on interactive multimedia courseware teaching methods.
\end{abstract}

Keywords: Multimedia Courseware; Interactive Technology; Application

\section{Introduction}

With the continuous deepening of new curriculum reforms, our country's teaching is also facing various reform requirements, and many new teaching methods are gradually emerging under this situation. In the process of deepening the reform of the new curriculum standard, the reform of the school's teaching methods is already a scientific and effective action to promote the reform. Classroom education, as a key part of teaching, determines the overall education level of a school and the comprehensive quality and ability of students. Breaking the traditional teaching methods and innovating teaching methods, the teaching methods of interactive multimedia courseware appear in people's vision.

\section{Introduction to multimedia courseware interactive technology}

\subsection{Multimedia courseware}

Multimedia courseware, in simple terms, is a tool used by teachers to assist in teaching. According to their own creativity, creators first classify and organize information as a whole, and then organize text, graphics, images, sound, animation, video and other media. The materials are integrated in the two aspects of time and space, so that they are integrated and given interactive characteristics, so as to produce a variety of wonderful multimedia application software products.

\subsection{Interactive multimedia courseware}

Interactive multimedia courseware is based on the video resources of the original multimedia courseware. It uses

This is an open-access article distributed under the terms of the Creative Commons Attribution Non-Commercial License (http://creativecommons.org/licenses/by-nc/4.0/), which permits unrestricted non-commercial use, distribution, and reproduction in any medium, provided the original work is properly cited. 
technical means to increase interactive functions. Learners can operate the content of the video resources through input devices, making the teaching process a two-way flow of information to realize the most effective use of teaching videos.

\subsection{The role of interactive technology of multimedia courseware in teaching}

It occupies an important position in the teaching classroom in the new era. First, it can expand the teaching content of the classroom. This is because interactive multimedia courseware is a teaching method based on Internet technology. It can make full use of knowledge on the Internet to help students learn knowledge and expand their horizons. Let it feel the charm of knowledge and finally achieve the goal of classroom teaching. Secondly, it helps to improve the professional ability of teachers. Although interactive multimedia courseware has concise and concise features, it involves a lot of content. Teachers must use scientific design methods to enter a large number of theories into the video of the interactive multimedia courseware. Based on the quality of learning, try to be as precise and accurate as possible to meet the learning needs of different students. Finally, the teaching method of interactive multimedia courseware helps to improve the interaction between teachers and students in the classroom. This is because interactive multimedia courseware is a modern teaching method. It pays more attention to interaction. Teachers need to consider the effects of students' learning. They must actively cooperate with students during the learning process. Finding problems in the teaching process can ensure the quality of interactive multimedia courseware teaching and enable students to master scientific learning methods to improve their learning ability.

\section{Realize the interactive technology and application of multimedia courseware}

\subsection{Conditions for realizing multimedia courseware interactive technology}

\subsubsection{Hardware infrastructure}

Micro classrooms, cameras, virtual video recording equipment, etc., use the above methods to record courseware of these hardware facilities of high quality. Obviously, DV and mobile phones can also meet the recording needs of teachers. As a result, the time and expense invested will continue to decrease. In addition to camera facilities, it is also possible to use screen recording software to complete the purpose of courseware recording. For example, most courseware uses recording software to record the teaching activities of the tablet. Now there are more software to choose from.

\subsubsection{Related production software}

After the recording of the multimedia courseware is over, special software is required to realize interactive development. According to the difference of the hardware equipment for recording the courseware, the development software used can also be divided into two different types. The video recording method requires software not only for recording, but also for interactive development. Therefore, in the process of clarifying the screen recording software, interactive development must be the basis. For example, Snap! ByLectora, AdobeCaptivate, Storyline, etc. all have relatively good interactions. For the software that realizes interactive development of screen-recording multimedia courseware, not only can the recorded courseware materials be imported from outside, but also interactive functions can be added to it. Flash can complete the interactive development of external video materials.

\subsubsection{Skills training for teachers in design, development and application}

On the one hand, the use of technical training can enable teachers to better understand the production and development techniques of interactive multimedia courseware, and try to arouse teachers' initiative in the development of such courseware. On another level, the teaching design of such courseware, blended learning and other training activities also need to be highly valued. From the above two perspectives as a starting point, to prevent teachers from "technical show", so that a large number of subject teachers can produce interactive multimedia courseware with their own characteristics. 


\subsection{Technical application of multimedia courseware interaction}

Flash is the mainstream software for making courseware or animation. It has rich functions and has a good realization in the research and development of interactive functions. There is a close relationship between the development of interactive multimedia courseware and the editing of videos. Flash's timeline, layers, buttons and other functions provide more ways to realize the editing of video materials and the development of interactive functions.

At present, there are a large number of multimedia production software, and the teacher must realize the development work through the corresponding software. Some of the software has a certain degree of intersection in function and implementation, such as AdobeCaptivate, Storyline, Camtasiastudio, etc. There is no obvious difference in function setting and development method. The paper will use AdobeCaptivate to realize the development of interactive functions. Compared with other software, AdobeCaptivate has better interactive capabilities. It can use screen recording to realize the development of simulation functions, edit multimedia files, and add interactive functions. In this type of software, Snap! ByLectora has more functions, and develops interactive multimedia courseware based on the well-known PowerPoint. Snap, setting the software in PowerPoint, is equivalent to becoming a plug-in of PowerPoint, and its implementation is different from other software. Use the screen recording method to make video data, and can add interactive functions and test questions in it, which is convenient to use. Based on the above-mentioned research on the availability and practicality of interactive multimedia courseware technology, the paper will develop interactive multimedia courseware cases based on Flash, Snap! ByLectora and AdobeCaptivate software. Mainly based on the differences in the recording methods of "multimedia courseware", the above three types of software are divided into two for case studies. In the process of developing multimedia courseware, the software used is Snap! ByLectora, AdobeCaptivate, based on interactive video. The software used in courseware development is Flash. The thesis will realize the development of embedded interactive multimedia courseware for test questions and simulation interactive multimedia courseware through relevant development software.

\section{Advantages brought by interactive multimedia courseware technology}

\subsection{The learning effect of students has improved}

In the learning process of students, the teaching of multimedia courseware interactive technology plays a very obvious role in improving student performance. The teaching of this technique can improve students' test scores and artistic quality. For example, multimedia courseware interactive technology teaching can improve students' intelligence and creativity, and develop students' left and right brains. Multimedia courseware interactive technology teaching has a certain effect on students' intelligence and creativity and can be developed as much as possible. The intelligence of students promotes students' memory. In the course of practice, it also shows that the use of multimedia courseware interactive technology in teaching can promote students to better memorize some boring vocabulary, formulas and concepts. In addition, multimedia courseware interactive technology teaching can also improve students' association and creativity. Neurophysiologists have proposed that the functions of the two hemispheres of the human brain are different. The left hemisphere has a conscious function, basically using language and logic to convey inner views, and has the function of learning words and algorithms. The right hemisphere has a subconscious role, basically using emotions and images to convey the inner world, and has the function of appreciating music and art. There are images and music in the multimedia courseware interactive technology teaching. Therefore, the multimedia courseware interactive technology teaching. The education of is conducive to better developing the potential abilities of students' right brains, and can encourage their left brains and right brains to think at the same time, making them smarter. Related research results show that nearly $70 \%$ of world-renowned scientists with high creativity. Their dominant brain lies in the right hemisphere. From the above research, it can be understood that multimedia courseware interactive technology can not only cultivate students' artistic thinking, but also integrate artistic thinking with scientific thinking, and enhance students' creative ability. 


\subsection{Improve students' interest in learning}

In the process of multimedia courseware interactive technology learning, the content taught by the teacher in the teaching activities can have a greater impact on the students. In the learning activities, if the teacher conveys a more pleasant feeling, the teacher and the student will form resonance, in this way, can further enhance students' enthusiasm and initiative for participation, so that they can actively participate in learning activities. On the contrary, if the content conveyed by the teacher in the teaching activities is relatively negative, the students must not be interested in the knowledge taught by the teacher, and the teacher cannot communicate with each other. Such content is not conducive to strengthening the students' interest in the teaching activities. It will also make them lose their internal motivation. In the process of multimedia courseware interactive technology teaching, the choice of content is very important. In educational activities, teachers need to guide students in content education so that they can cultivate learning content. In practical teaching activities, the teacher's influence on students' formation is very obvious, especially students, who are in the transitional period of knowledge. During this period of time, the guidance of the teacher plays a critical role and the teacher must pass positive attitudes and teaching methods guide students' learning activities, so that they can arouse their learning enthusiasm and initiative.

\section{Conclusion}

Through the analysis of the above articles, we have learned about the interactive technology of multimedia courseware and its role in teaching applications. At the same time, we have made a detailed introduction to the application of its technology. In addition, through an example of the course, the difference between using interactive multimedia courseware and not using interactive multimedia courseware in teaching was explained. After that, the problems in the development of teaching were analyzed, and then corresponding solutions were proposed for the problems. Hope to help related researchers.

\section{References}

1. Liang B. The interaction design of multimedia course based on web. Modern Educational Technology 2001; 11(3): 48-51, 65.

2. Chen L. Exploration and research on interactive design of multimedia courseware (in Chinese). Course Education Research 2014; (2): 218-219.

3. Su Y. Application of multimedia interactivity in network courseware. Value Engineering 2013; (22): $260-261$. 